\title{
La relación entre la parte especial y la general del derecho penal
}

\author{
Orlando Humberto de la Vega Martinis*
}

\begin{abstract}
RESUMEN
El texto defiende la necesidad de separación de las partes especial y general del derecho penal, así como la prioridad lógica de la primera sobre la segunda; tanto la separación entre ambas partes como la prioridad de la parte especial descansan en argumentos de tipo funcional. Su objeto es despejar el camino para una sistematización de la parte especial del derecho penal ajena a la teoría general del delito.
\end{abstract}

Función de integración; función de paréntesis; parte especial y legalidad

\section{The relationship between the special and the general part of criminal law}

\begin{abstract}
The text defends the need to separate the special and the general parts of criminal law, as well as the logical priority of the first over the second. Both, the separation between the two parts and the priority of the special part rest on arguments of a functional type. Its purpose is to clear the way for a systematization of the special part of criminal law alien to the general theory of crime.
\end{abstract}

Integration function; parenthesis function; special part and legality

* Abogado de la Universidad Externado de Colombia. Doctor en Derecho, Universidad de Bonn, Alemania. Profesor Asistente del Departamento de Derecho Penal, Pontificia Universidad Javeriana, Bogotá, Colombia. ORCID: https://orcid.org/0000-0002-3529-9810. Correo electrónico: odelavega@ javeriana.edu.co

Versiones preliminares del artículo fueron discutidas en el seminario permanente de doctorado de la Facultad de Ciencias Jurídicas de la Pontificia Universidad Javeriana y en el semillero de investigación de derecho penal de la Facultad de Jurisprudencia del Colegio Mayor de Nuestra Señora del Rosario, a cuyas directoras, Prof. Dr. Liliana Sánchez y Prof. Dr. María Camila Correa, expreso mi gratitud por la oportunidad de someter a prueba las ideas presentadas en el texto; en especial agradezco las observaciones del Prof. Dr. Hernán Darío Orozco López, comentarista del texto en el marco del seminario permanente. Las valiosas sugerencias recibidas de los dos árbitros anónimos, en especial del árbitro anónimo A, contribuyeron a hacer más comprensible el argumento global.

Artículo recibido el 2.9.2020 y aceptado para su publicación el 11.6.2021. 


\section{INTRODUCCIÓN}

E n una decisión del año 2011 la Corte Suprema de Justicia de Colombia absolvió a una juez que le dijo a sus subalternos que eran unos estúpidos, unos porquerías, que no servían para nada y que eran unos mugres $^{1}$; pero el argumento en el que descansó la corte no derivó de un estudio del art. 220 del código penal colombiano, el que define la injuria como imputación deshonrosa, sino en una aplicación del art. 11 del mismo código, el que hace depender la punibilidad de la lesión a un bien jurídico. Si el art. 220 define el delito de injuria y es vinculante para la práctica del derecho colombiano, una dogmática del delito de injuria propia de la parte especial debería ocuparse de la estructura de la declaración imputativa y de su diferencia con la declaración expresiva ${ }^{2}$; en Colombia, además, urge aclarar si el alcance de la actual definición legal de la injuria como imputación debe asociarse solo a la declaración imputativa, en contraste con la antigua definición de injuria del código penal de 1936 como ataque al honor por cualquier medio eficaz para divulgar el pensamiento, la que podría asociarse tanto a las declaraciones imputativas como a las expresivas. Clarificar este aspecto permitiría perfilar el bien jurídico protegido fragmentariamente por el delito de injuria; afirmando, por ejemplo, que el bien jurídico solo está protegido frente a declaraciones imputativas. Pero, en lugar de una dogmática del delito de injuria, la corte se dio por satisfecha afirmando que "uno de los presupuestos del punible de injuria es que la atribución de actos deshonrosos tenga la real capacidad de menoscabar la honra y el honor de la víctima, lo que en este caso materialmente no tiene existencia” 3 .

De esta forma, la corte ignoró el radio de aplicación del art. 220 (¿cubre las declaraciones expresivas de la juez?) y lo sustituyó por su idea preconcebida de bien jurídico. Este proceder de la corte no es nuevo; en una decisión de 1963 la corte absolvió a un hombre que sostuvo relaciones sexuales consentidas con una mujer de 15 años, pese a que el art. 326 del código penal de 1936 castigaba con pena a quien corrompiera, mediante acceso carnal consentido, a una mujer mayor de 14 años y menor de 16. En esa ocasión la corte afirmó que el bien jurídico protegido por el art. 326 era "la honestidad sexual", siendo "incuestionable que una mujer que ha faltado a la castidad no es sexualmente honesta" ${ }^{4}$. En estos dos casos la corte prefirió enfocarse en un argumento abstracto, con consecuencias diversas; en el primer caso desatendió un problema interpretativo concreto, mientras que en el segundo desatendió la ley.

Sin un estudio estadístico de la jurisprudencia colombiana puede resultar prematuro afirmar que la corte abusa de la parte general del derecho penal; aún así, resulta ilustrativo lo afirmado por la corte en una decisión de 1965: "[L]a parte general está destinada a sentar las bases o principios, resumen de una filosofía penal, que han de servir

\footnotetext{
${ }^{1}$ Jurisprudencia \& Doctrina, 2012, p. 823.

${ }^{2}$ Mañalich, 2020, pp. 51-54.

3 Jurisprudencia \& Doctrina, 2012, p. 823.

${ }^{4}$ GJ CI, 1963, p. 335.
} 
como de guía en la parte especial" 5 , de donde se derivaría una "superioridad intrínseca de las normas de la llamada parte general"6-7. Esta observación de la corte, favorable a una cultura jurídica que privilegia un concepto material de delito por encima de uno legal, ni siquiera estaba conectada con el caso concreto sometido a juicio. Este consistía en definir el límite máximo de pena previsto para la estafa calificada de acuerdo con el código penal de 1936, cuyo art. 410 fijaba el máximo en 14 años de prisión, mientras que el art. 45 fijaba en 8 años la duración máxima de la pena de prisión. En cuanto a su destinatario no hay diferencia entre una norma que fija un máximo de pena de prisión en 14 años y otra que lo fija en 8; ambas son normas de sanción dirigidas a los funcionarios encargados de la individualización de la pena. Así visto, difícilmente puede decirse que la corte adjudicó responsabilidad por un caso concreto de estafa; pues para absolver esa tarea dentro del límite temporal fijado por la regla de prescripción un paso decisivo era averiguar la voluntad del legislador respecto del máximo de la pena de prisión prevista para la estafa, no verificar si la norma de sanción de la parte especial se ajustaba a un supuesto límite material de la pena contenido en la parte general y vinculante en virtud de su contenido "filosófico".

La particularidad de este último caso, a saber, confusión entre destinatarios de las partes especial y general, se repitió en una decisión de la Corte Constitucional colombiana el 2021 que declaró inconstitucional la regla contemplada en el art. 130, segundo párrafo. La regla en mención definía como tentativa de homicidio el abandono "en sitios o circunstancias donde la supervivencia del recién nacido esté en peligro"; a juicio de la corte, dicha definición legal desconocería el principio de legalidad "[a]l no satisfacer las exigencias de claridad, especificidad y precisión que requiere la tipificación de una circunstancia de agravación" 8 . Esta definición legal no pretendía ser, como cree la corte, una norma de comportamiento dirigida al ciudadano, sino una regla dirigida al funcionario para que, bajo ciertas condiciones, adecuara un comportamiento de abandono como tentativa de homicidio. En una práctica madura del derecho una regla tal puede resultar extraña ${ }^{9}$, pero la solución de la corte debilita la democracia en tanto que impone una comprensión material de delito, degradando la soberanía del pueblo.

Los ejemplos anteriores ofrecen una variedad de problemas teóricos concretos, pero también se dejan reconducir a un punto en común: la relación entre la parte especial y la general del código penal. En una práctica del derecho con "agencias que efectivamente aplican y ejecutan la ley" 10 deberían ser esas agencias, es decir las cortes, quienes fijaran dicha relación; sin embargo, por lo menos acotado a los ejemplos anteriores, queda la sensación de que la corte ignora la ley, o al menos la parte especial. Al desconocer que

\footnotetext{
${ }^{5}$ GJ CXIII y CXIV, 1974, p. 288.

${ }^{6}$ GJ CXIII y CXIV, 1974, p. 288.

${ }^{7}$ También dijo la corte que las disposiciones de la parte general son normativas; para una comprensión no normativa de la parte general, sino descriptiva, Moore, 1997, p. 9 s.

${ }^{8}$ Corte Constitucional. Sentencia C-093.

${ }^{9}$ La idea de "práctica madura del derecho" la tomo de HART, 1961, p. 77 y 97, y HART, 1982, p. 257.

${ }^{10}$ HaRT, 1982, p. 257; RAZ, 1975, p. 132.
} 
el injusto concreto y su pena están en la parte especial, la corte privilegia la razón de su decisión por encima de su decisión del caso. Este defecto, compartido por la jurisprudencia alemana de principios del siglo XX, fue uno de los motivos que movió a Karl Binding a escribir su parte especial ${ }^{11}$. La crítica de Binding es la siguiente: si la corte, en lugar de concentrarse en la decisión del caso, se concentra en la razón de la decisión fomenta un poderoso prejuicio; pues esa misma razón, en otros casos, puede resultar "errática". De allí que el deber de la ciencia, según Binding, sea combatir decididamente falsos prejuicios y razones erráticas ${ }^{12}$.

Y hay que abonarle a Binding su aporte, pues una decisión del órgano de cierre de la jurisdicción penal ordinaria alemana, el BGH, de 1955, resolvió un asunto que planteó una tensión entre la parte especial y la general del derecho penal, similar a la de los ejemplos colombianos, dando prioridad a la parte especial. Los hechos que ocuparon la atención del BGH fueron los siguientes: una mujer visitó a su prometido, quien estaba privado de la libertad en una estación de policía, con un serrucho escondido dentro de una barra de chocolate; el plan del prometido era serruchar los barrotes de la ventana de la celda y fugarse, pero la mujer fue detenida cuando ingresó a la estación de policía ${ }^{13}$. La defensa de la mujer alegó que la conducta era un acto preparatorio, y por tanto impune, del $§ 120$ del código penal alemán; el BGH rechazó el argumento porque "[c]uando un hecho está consumado, tentado o apenas preparado solo puede averiguarse en atención a un tipo legal específico" 14 . Es decir, la pauta de comportamiento ajustado a derecho de la mujer está en la prohibición de ayuda a la fuga del $\$ 120$ y no en criterios generales acerca de la distinción entre preparación y ejecución; estos últimos dirigidos al juez.

El punto de partida de Binding para proporcionar a la jurisprudencia una guía científica fue circunscribir su análisis al, en ese entonces, recién expedido código penal alemán y, en particular, a su parte especial ${ }^{15}$. Ya desde el prólogo a la primera edición del tomo 1 de su obra dedicada al estudio de la parte especial de 1896, Binding narra cómo descubrió la prioridad de la parte especial frente a la general: para poder desarrollar científicamente la parte general se necesita, antes, dominar la parte especial ${ }^{16}$. Y en el prólogo a la segunda edición de esa misma obra, de 1902, Binding resaltó la independencia de la parte especial frente a la general: una presentación de la parte especial no es una mera repetición de los temas de la parte general ${ }^{17}$. Estos dos hallazgos de Binding constituyen los criterios que marcan la relación entre las partes especial y general del derecho penal alemán. Esta afirmación parece pacífica en la doctrina alemana ${ }^{18}$. Por ejemplo, en lo que tiene que ver con la prioridad de la parte especial frente a la general,

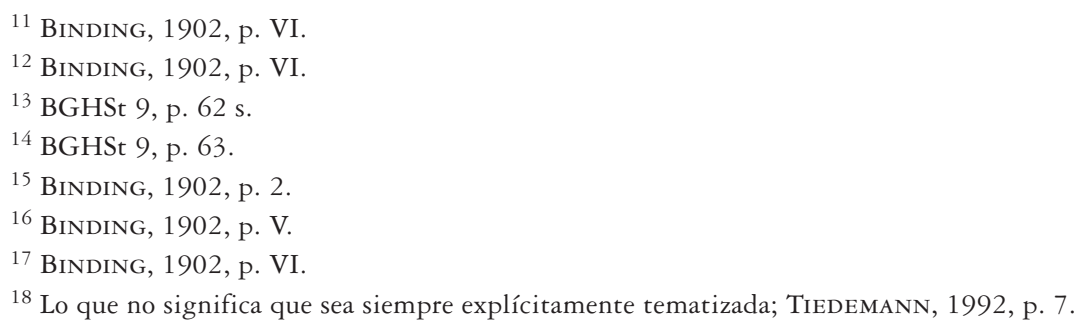


Reinhart Maurach afirma que " $[1]$ a parte general ... es el hermano más pequeño de la parte especial" ${ }^{19}$, porque los temas de que se ocupa la parte general, antes de ser desarrollados, tienen que mostrar capacidad de rendimiento respecto de cada uno de los delitos de la parte especial; por el contrario, los temas propios de la parte especial no se dejan "ubicar antes del paréntesis" 20 , es decir, no tienen conexión con la parte general.

$Y$ en cuanto a la independencia entre ambas partes Maurach hace la siguiente observación: " $[\mathrm{L}] \mathrm{a}$ explicación del hurto es, en últimas, independiente de si se incluye el ánimo de apropiación en el tipo subjetivo pero el conocimiento de la ajenidad de la cosa en la culpabilidad ... o de si toda la orientación volitiva del autor se sitúa en el tipo subjetivo y en el marco de la culpabilidad solo se examina la relevancia de la voluntad para la responsabilidad penal del autor" ${ }^{21}$. La observación de Maurach desagrega del hurto aspectos propios de la estructura general del delito; es decir, aspectos que no solo valen para el hurto, sino para cualquier delito y que, en consecuencia, son incapaces de individualizar al hurto. Con la estructura general del delito no puede contestarse, por ejemplo, qué es el hurto, si su objeto de protección es la propiedad o el patrimonio, si el objeto de la acción puede ser una cosa incorporal o solo puede ser una corporal, cómo se define el "apoderamiento", cuándo se consuma, qué rol juega el "propósito de obtener provecho”, cuál es su diferencia con el daño en bien ajeno, cuál con la estafa; la respuesta a estas preguntas está en la parte especial del derecho penal ${ }^{22}$.

La unanimidad con que la doctrina alemana comprende la relación entre la parte especial y la general del derecho penal en torno a los criterios expuestos permite resaltar una comprensión, visible en la jurisprudencia colombiana, que hace depender la parte especial de la general. La principal contribución del presente artículo es mostrar las razones lógicas, funcionales y, en menor medida, históricas en contra de esa dependencia.

De acuerdo con la doctrina alemana la parte general del derecho penal se desagregó, en un ejercicio inductivo, de la parte especial ${ }^{23}$; de ahí surgieron dos caminos para reunificar dos partes originalmente unidas. El primero, conocido como función integradora, consiste en integrar ambas partes a la sombra de la parte general; el segundo, conocido como función de paréntesis, consiste en ubicarlas una al lado de la otra ${ }^{24}$. En todo caso, ambos caminos tuvieron como punto de partida a la parte especial; qué se hace después con la parte general depende de la preferencia por un proyecto asimilador o diferenciador de los aspectos que conforman la totalidad del derecho penal. La preferencia por un proyecto diferenciador, mayoritaria en la doctrina alemana, resulta comprensible en una tradición que separó la parte general de la especial para hacer operativa la idea de

19 Maurach, 1959, p. 3.

${ }^{20}$ MaUrach, 1959, p. 4; sobre el significado de esta expresión véase, abajo, II.2.

${ }^{21}$ Maurach, 1959, p. 4.

${ }^{22}$ Así desarrolla el tema KINDhäUSER, 2017a, § 2, pp. 36-67; la remisión a la parte especial la vemos en Roxin, 2006, § 1/15, p. 7.

${ }^{23}$ Fincke, 1975, p. 3 s; Tiedemann, 1992, pp. 8-10.

${ }^{24}$ FINCKE, 1975, p. 8. 
culpabilidad $^{25}$; mientras que la importancia que en esa misma tradición tiene el pensamiento sistemático ${ }^{26}$ explica el relacionamiento de dos partes independientes.

En Colombia se recibió la idea de culpabilidad en un "ambiente hermenéutico pobre" 27 ; por ejemplo, el legislador colombiano de 1980 convirtió en derecho positivo los conceptos de la teoría general del delito de origen alemán, tal como estos eran entendidos por los comisionados que redactaron el proyecto de código ${ }^{28}$. Pero la tendencia, propia de los siglos XV y XVI, a que la ley tomara "el carácter de un tratado, conservando la forma doctrinaria de sus fuentes" ${ }^{29}$, ya había sido ampliamente superada en el espacio cultural alemán. Martin Fincke, por ejemplo, resalta en 1975 la ausencia en el código penal alemán de disposiciones proclamativas, declarativas y definitorias como una característica del derecho penal alemán y, además, constata una tendencia a sospechar de los preámbulos y principios contenidos en códigos extranjeros ${ }^{30}$. Y en 1992 Klaus Tiedemann se refiere, con asombro, a la definición de los elementos del delito en el código penal colombiano de 1980, según Tiedemann operada "bajo el influjo del gran Alfonso Reyes E."31; en opinión de Tiedemann, los conceptos de la teoría general del delito no solo no están presentes en la parte general del código penal alemán, sino que ni siquiera la describen de manera aproximada ${ }^{32}$.

Este contraste entre la forma como el legislador colombiano entendió la doctrina alemana y la forma como dicha doctrina se veía a sí misma refuerza la hipótesis de un ambiente hermenéutico pobre en Colombia a finales del siglo pasado; un ambiente marcado, en particular, por un bajo nivel de estudio de la legislación nacional ${ }^{33}$. En ese contexto, adverso al desarrollo de un pensamiento sistemático, se recibió la idea de culpabilidad con plena consciencia respecto de su carácter general; es comprensible, entonces, que a partir de ese momento se constate cierto predominio de la parte general, entendida incluso como capaz de integrar en sí a la parte especial ${ }^{34}$. La ausencia de traducciones españolas de parte especial alemana probablemente ha contribuido a

\footnotetext{
${ }^{25}$ FINCKE, 1975, p. 10.

${ }^{26}$ Hefendehl, 2003, p. 128.

27 LÓPEZ, 2004, p. 17.

${ }^{28}$ Comisión Redactora del Código Penal, sin fecha, p. 13; De-La-Vega, 2019, p. 111.
}

${ }^{29}$ HälsCHNER, 1855, p. 84. La similitud es interesante, pese a los cinco siglos de diferencia, porque mientras que las codificaciones estudiadas por Hugo Hälschner eran obra de un príncipe, dirigidas unilateralmente a sus súbditos ignorantes del derecho, el código penal colombiano de 1980 tuvo como destinatario al pueblo colombiano, ignorante de los conceptos de la doctrina alemana, mediante un decreto del ejecutivo; acerca de la posibilidad de que los conceptos de la parte general tengan un alto nivel de especificidad y, por tanto, no sean comprendidos por sus destinatarios, RoBINSON, 2005, p. 378.

${ }^{30}$ Fincke, 1975, p. 20 s.

31 Tiedemann, 1992, p. 10, pie de página 16, bastardilla en el original.

32 Tiedemann, 1992, p. 10.

${ }^{33}$ La producción bibliográfica de todo el siglo XIX se reduce al libro de José Vicente Concha, que contiene parte general y especial; la de la primera mitad del siglo XX, comprensiva de ambas partes, se agota con el libro de Ángel Martín Vásquez Abad y con el breve comentario de Arcesio Aragón.

34 PÉrez, 1968, p. 1 s; pero es importante resaltar que en ningún momento de su desarrollo de la parte especial se ve materializada esa idea integradora. 
mantener esa tendencia al predominio de la parte general ${ }^{35}$. La hipótesis que quiero explorar en el presente artículo es que una correcta comprensión de la relación entre parte especial y general del derecho penal es el presupuesto necesario para desarrollar el estudio de parte especial en Colombia y, de paso, acotar el estudio de parte general a su justa proporción.

En lo que sigue, entonces, presentaré razones a favor de la independencia entre las partes especial y general del derecho penal, así como a favor de la prioridad de la primera sobre la segunda. Como se verá, ambas ideas descansan en razones de tipo funcional; es decir, asociadas a la distinta función de una y otra parte. A propósito de la independencia, mi objetivo es desvelar el riesgo, latente en la función integradora, de retroceso a un concepto material de delito desvinculado de la idea de legalidad; y a propósito de la prioridad, mi objetivo es mostrar el carácter estrictamente lógico del argumento. La presencia en la bibliografía de comentaristas de la codificación europea se explica, no por una pretensión histórica, sino por el rol protagónico que jugaron estableciendo las bases de un derecho penal dividido en partes general y especial; la presencia de autores de la tradición del common law, de otra parte, se explica por la claridad con la que desagregan la parte especial de la general del derecho penal, pero también porque su inclusión muestra que el tema no es patrimonio exclusivo de la doctrina alemana.

\section{INDEPENDENCIA ENTRE LAS PARTES ESPECIAL Y GENERAL}

Tanto el código penal alemán como el código penal colombiano se dividen en parte general y parte especial. La parte especial del actual código penal colombiano data de 1936 y su antecedente directo es el código penal italiano de $1930^{36}$; la parte general del actual código penal colombiano data de 1980 y es el resultado del proceso de legalización de los conceptos doctrinales vigentes en Alemania en la primera mitad del siglo XX. Por su parte, el código penal alemán es heredero de las codificaciones regionales anteriores a 1871; y estas, junto con el código penal francés de 1810, fueron los primeros en distinguir parte general y parte especial ${ }^{37}$. Una explicación usual de esta innovación es que ella correspondería al interés de la legislación en una técnica racional y sistemática, y este interés descansaría en la convicción de la época en la posibilidad de

${ }^{35}$ Con la notable excepción de Delgado, 1979, p. 94.

${ }^{36}$ La influencia del código penal italiano de 1930, así como la de su antecesor de 1889, sobre la parte especial del código penal de 1936 resulta notoria en los trabajos preparatorios de este último; COMISIÓN DE Asuntos Penales y Penitenciarios, 1938, p. 84; Comisión de Asuntos Penales y Penitenciarios, 1939, pp. 6 y 30, entre otras. La doctrina colombiana, por su parte, interpretó el código penal de 1936 ayudada del italiano de 1930; ArAGón, 1938, p. 110, entre otras.

${ }^{37}$ FINCKE, 1975, p. 4; sobre la Allgemeine Landrecht für die preußischen Staaten de 1794, HäLSCHNER, 1855, pp. 189-230; sobre el código penal bávaro de 1813, HäLSCHNER, 1881, § 21, p. 46 s; sobre el código penal francés de 1810, Garraud, 1888, pp. 93-102; GARraud, 1912, pp. 49-55; sobre la codificación en general en el espacio cultural francés, Rossi, 1872, pp. 348-354. 
un sistema ${ }^{38}$ libre de contradicciones ${ }^{39}$. Hoy sabemos que la carga de liberar al sistema de contradicciones no puede descansar, exclusivamente, en la ley; esta visión ingenua no es más que parte del folclor existente en torno al positivismo jurídico ${ }^{40}$. Así, P.J.A. Feuerbach, un contemporáneo del período codificador, era consciente de la posibilidad de vacíos y contradicciones en la ley y precisamente veía ahí la importancia de un método de interpretación de la ley cuya tarea principal fuera averiguar la voluntad del legislador ${ }^{41}$.

La alusión a Feuerbach es interesante porque él, como profesor, dividió el estudio del derecho penal en dos partes: una "parte filosófica o general del derecho penal" 42 y una "parte positiva o especial del derecho penal" 43 . Sin embargo en su rol de legislador, al redactar el código penal bávaro, no se limitó a codificar la parte especial, sino que convirtió en derecho positivo algunos criterios generales de la punibilidad de los hechos antijurídicos, con la finalidad de minimizar la posibilidad de que la jurisprudencia o la doctrina malinterpretaran la voluntad del legislador ${ }^{44}$; por ejemplo, en el libro primero de dicho código, titulado "Disposiciones legales generales sobre crímenes y delitos", arts. 37,57 y 58, se regula la consumación y la tentativa del delito. Y no es casualidad que esa regulación sea idéntica al desarrollo conceptual visible en el $\S 42$ de su Tratado ${ }^{45}$; mientras que los aspectos de su Tratado que a primera vista contarían como filosóficos no fueron incorporados al código penal bávaro ${ }^{46}$.

En la medida en que la Allgemeine Landrecht für die preußischen Staaten de 1794, el código penal francés de 1810 y el código penal bávaro de 1813 incorporaron una parte general no parece adecuado contraponer la parte especial o positiva del derecho penal a una parte filosófica o general; antes bien, desde ese momento resulta impensable, en el derecho penal continental europeo, un código penal sin dicha división ${ }^{47}$. De otra parte, no parece correcto acotar la influencia de los temas usualmente asociados a la filosofía 48 solo a la parte general del derecho penal; antes de la codificación, por ejemplo, la práctica del derecho penal común europeo reprimía con pena la sodomía y dejaba impune la

38 Esta "nueva concepción de sistema jurídico" sustituye los principios del derecho natural por las normas de derecho positivo; Alchourrón y Bulygin, 2012, p. 79.

${ }^{39}$ Fincke, 1975, p. 4; Tiedemann, 1992, p. 8. Es importante resaltar que "el ideal de completitud" no es "un ideal político que responda a una determinada ideología" sino "un ideal puramente racional"; Alchourrón y Bulygin, 2012, p. 234.

40 Atria, 2016, pp. 102 y 110. Aura Helena Peñas Felizzola presenta esta visión de la ley como modelo de racionalidad en la génesis del sistema penal colombiano; PEÑAs, 2006, pp. 162-172 y 255-278.

${ }^{41}$ Feuerbach, 1799, pp. 192-196 y 199.

42 Feuerbach, 1828, p. 11.

43 Feuerbach, 1828, p. 109.

${ }^{44}$ FinCKe, 1975, p. 18 s.

45 Feuerbach, 1828, § 42, p. 33 s.

${ }^{46}$ Fincke, 1975, p. 18 s; quien además hace notar que el propio P.J.A. Feuerbach no tenía clara la razón de su división entre parte general y especial.

${ }^{47}$ FinCKE, 1975, p. 8.

${ }^{48}$ Me refiero a la idea, atribuida a Ludwig Wittgenstein, de que la filosofía no tiene objeto de estudio; STERN, 2004, pp. 121-132. 
violación marital, siempre que esta se materializara en un coito vaginal, con fundamento en el modelo político criminal de la teología moral escolástica. El modelo político criminal de la ilustración, activamente influenciado por el pensamiento filosófico liberal, abolió la categoría de delitos sexuales y trasladó algunos de los antiguos delitos sexuales, por ejemplo la violación, a la categoría de delitos contra la libertad ${ }^{49}$. No hay más filosofía en la parte general del derecho penal que en la especial ${ }^{50}$; pero sí es posible constatar un menor desarrollo legislativo en la parte general, seguido de una exigencia científica por cubrir el faltante mediante el recurso a "principios filosóficos" 51 .

\section{Función integradora}

En esa senda que asigna a la filosofía la tarea de sistematizar el conocimiento científico destaca, en el campo del derecho penal, el nombre de Adolfo Merkel, quien, a finales del siglo XIX, propuso seguir el camino de lo especial a lo general apoyado en su comprensión de la relación entre filosofía del derecho y derecho positivo. Merkel observó que el desarrollo dogmático de algunos asuntos de derecho penal positivo llevaba a preguntas generales. Como ejemplo planteó la pregunta por el límite de la estafa punible, la que encierra la pregunta por la relación de aquella con la mera estafa civil, y esta segunda pregunta, a su turno, lleva a la pregunta más general por la relación entre la responsabilidad jurídico civil y la jurídico penal, la que, finalmente, lleva a la pregunta por la relación entre los elementos de la lesión del derecho y los del crimen en sentido amplio ${ }^{52}$. Transitar el camino de lo especial a lo general implica progreso; no hacerlo, conformismo con respuestas provisionales ${ }^{53}$.

Esta comprensión merkeliana de la relación entre lo especial y lo general no coincide con la división legal del derecho penal en partes general y especial, pero sí puede sumarse a una forma doctrinal de abordar dicha división. Al respecto Merkel constató dos tendencias científicas: "[U]na expansión progresiva de la ciencia y una concentración progresiva de la misma" "54; la primera, que suministra el contexto de la segunda, es la actividad filosófica. Y la fuerza centrípeta de esta última, agrega Merkel, fija los elementos a los que deben reconducirse los hallazgos de un determinado campo, así como

${ }^{49}$ BASCUÑ́́N, 1997, pp. 75-77.

${ }^{50}$ Incluso podría decirse que la parte especial monopoliza la filosofía, mientras que la parte general está dominada por la sicología; en esa dirección Michael S. Moore afirma que "explicar la mente y la moral es lo mismo que explicar el derecho”; Moore, 2002, p. 623. Sin embargo, el comisionado Luis Carlos Giraldo Marín, en 1979, entendía, siguiendo una decisión aislada de la Corte Suprema de Justicia de Colombia, que la misión de la parte general es "sentar las bases o principios, resumen de una filosofía penal, que han de servir de guía en la Parte Especial”, lo que le hacía pensar que las normas de la parte general pertenecen "a una categoría superior”; Comisión RedaCtora del Código Penal, 1981, p. 257. Es importante resaltar que esta observación no suscitó ningún comentario de los restantes comisionados.

51 Feuerbach, 1799, p. XXIV.

52 Merkel, 1874, p. 3.

53 Merkel, 1874, p. 4.

${ }^{54}$ Merkel, 1874, p. 6. 
la relación general entre dichos elementos. La ciencia es una sola y en ella confluyen las funciones de sus partes; el trabajo filosófico garantiza la unidad ${ }^{55}$. En la ciencia del derecho este trabajo filosófico conduce a una parte general de la que brotan las normas especiales, así como las ramas y las hojas brotan del tronco de un árbol ${ }^{56}$. Esta metáfora permite asignarle a la parte general una función integradora en su relación con la parte especial; de acuerdo con dicha función la parte general contendría en sí, como genus proximum, sus conceptos subordinados 57 .

En esta comprensión integradora Merkel no estaba solo; ya antes Hugo Hälschner, en su obra dedicada al estudio de la parte especial del derecho penal prusiano, afirmaba lo siguiente: "Todo lo que de alguna forma aparece como momento esencial del tipo especial nunca es solo algo especial, sino, al mismo tiempo, una generalidad que, desde esa perspectiva, exige su debida consideración en la parte general" 58 . Hoy siguen esta tendencia generalizadora de la parte especial Günther Jakobs ${ }^{59}$ y Michael Kubiciel ${ }^{60}$. La estrategia homogeneizadora de Jakobs descansa en un concepto ideal de persona en derecho, entendida como punto de referencia de deberes y derechos ${ }^{61}$; en desarrollo de esa estrategia Jakobs considera que agrupar los distintos tipos de la parte especial de acuerdo con la idea de bien jurídico no es más que una "mezcolanza" indigna de tratamiento científico hasta tanto no se muestre como "una realización de lo general" 62 . Jakobs tiene razón al señalar a la persona como punto de partida del derecho ${ }^{63}$; pero, como el punto de partida cartesiano en filosofía muestra, la verdad de ese planteamiento no necesariamente lleva a desarrollos óptimos ${ }^{64}$. Juan Pablo Mañalich destaca, de manera crítica, las siguientes conclusiones jakobsianas para la parte especial: el cuerpo como propiedad de la persona; injuria sin lesión del honor; homicidio a petición como delito contra el interés general en la madurez del consentimiento; falsedad documental como delito contra la persona; y constreñimiento como delito contra la libertad jurídicamente garantizada ${ }^{65}$.

55 Merkel, 1874, p. 6.

56 Merkel, 1874 , p. 7.

${ }^{57}$ FinCKe, 1975, pp. 8 y 19.

58 HälsChNER, 1868, p. 1; HäLSCHNER, 1884, p. 1.

59 JakоBs, 2001, p. 810, con reproducción textual de la cita de Hugo Hälschner recién mencionada; el subtítulo del texto es, por lo demás, explícito: "Al mismo tiempo un aporte a la generalización de la parte especial”; el subtítulo se repite en JАковs, 2008, p. 649; JАковs, 2003, p. 63, donde se propone homogeneizar lo especial.

${ }^{60}$ Kubiciel, 2013 , p. 4; en la p. 26 apoya su proyecto generalizador de la parte especial con cita de Hugo Hälschner.

${ }^{61}$ Mañalich, 2019, p. 615.

62 JakoBs, 2003, p. 63.

${ }^{63}$ Planteamiento también visible en Köstlin, 1858, pp. 1 y 417.

${ }^{64}$ Apel, 1973, p. 693, quien señala que el punto de partida cartesiano, es decir el pensamiento humano, es vinculante para la ética, pero que el mismo debe ser combinado con un "juego del lenguaje trascendental" para, de esa forma, refutar el solipsismo cartesiano.

${ }^{65}$ MaÑalich, 2019, pp. 618, 621, 624, 629 y 632, respectivamente. 
Dejando de lado lo problemática que puede resultar la compatibilidad de conclusiones integradoras como las recién enunciadas con el derecho penal vigente en el lugar donde fueron enunciadas ${ }^{66}$, resulta crucial subrayar que esta integración u homogeneización, como su nombre sugiere, favorece una prioridad metodológica por la asimilación de las partes general y especial del derecho penal. Esa elección no es, en sí misma, incorrecta. Sin embargo, como Robert B. Brandom pone de presente, los proyectos asimiladores están en peligro de no dar cuenta de las diferencias ${ }^{67}$; esta observación es importante porque las conclusiones homogeneizadoras de Jakobs materializan el peligro anunciado por Brandom: no dan cuenta de lo especial de la parte especial. Así, aunque sea posible reconducirlos a un punto en común, vale la pena distinguir entre lesión corporal y daño en bien ajeno, por ejemplo ${ }^{68}$.

Y lo mismo puede decirse del esfuerzo de Kubiciel por borrar la distinción entre una dogmática de la parte general orientada a la teoría de la pena y la imputación, de un lado, y una dogmática de la parte especial referida al bien jurídico, del otro ${ }^{69}$. Sobre esta distinción volveré en la sección III. Antes deseo destacar el escepticismo de Kubiciel frente a la teoría del bien jurídico y el correlativo déficit de racionalidad que le asigna al método de interpretación objetivo teleológico de los tipos penales ${ }^{70}$; una parte especial ordenada de acuerdo con la idea de protección de bienes jurídicos no sería más que "un catálogo de temas organizable de cualquier forma" 71 y un intérprete que emplee el método objetivo teleológico no estaría apoyado en "verdaderas razones"72. La parte especial solo será científica, de acuerdo con Kubiciel, si se generaliza en torno a la teoría de la pena y de la imputación ${ }^{73}$.

Es curioso que unas conclusiones integradoras puedan resultar incompatibles con la parte especial, pues la parte general, a la que se asigna dicha función integradora, se habría desagregado de la parte especial; esa es la razón de que la parte general contenga en sí a la especial. La clave para entender esta incompatibilidad está en evaluar el nivel de compromiso con la parte especial como punto de partida de la inducción que lleva a la parte general. Si en lugar de tomar como punto de partida los delitos de la parte especial se toma como punto de partida un concepto material de delito es perfectamente posible que el esfuerzo integrador asignado a la parte general riña con la parte especial; la parte general se convierte, así, en juez de la parte especial. El actual código penal colombiano, que tomó los conceptos de la teoría general del delito de origen alemán en un contexto marcado por un bajo nivel de estudio de la parte especial, brinda un buen

${ }^{66}$ MaÑAlich, 2019, p. 631, quien destaca que Günther Jakobs cree que una discrepancia de su posición con el derecho positivo sería una razón a favor de la corrección de su propia posición.

${ }^{67}$ BRANDOM, 2000, p. 3.

${ }^{68}$ Köstlin, 1858, § 13, p. 179.

${ }^{69}$ Kubiciel, 2013 , p. 6.

${ }^{70}$ Kubiciel, 2013, p. 48 s.

${ }^{71}$ Kubiciel, 2013, p. 114.

72 Kubiciel, 2013, p. 114.

${ }^{73}$ Kubiciel, 2013, p. 126. 
ejemplo de esa incompatibilidad entre conclusiones integradoras de parte general y la concreta parte especial. Como se verá en la sección III, la parte general es ciega frente al bien jurídico ${ }^{74}$; solo la parte especial define el injusto en una práctica del derecho vinculada a la idea de legalidad. Sin embargo, el código penal colombiano, a diferencia del código penal alemán, incluye en su parte general un grupo de disposiciones que, bajo el título "De las normas rectoras de la ley penal colombiana", informarían la interpretación del código. Una de ellas, la contenida en el art. 11, define la antijuridicidad, uno de los conceptos tomados de la teoría general del delito de origen alemán, en términos de la proximidad al menoscabo en la sustancia del bien jurídico ${ }^{75}$.

El concepto material de delito al que responde el art. 11 no toma en consideración que la parte especial tiene delitos cuya arquitectura típica ${ }^{76}$ descansa en el daño de peligro abstracto, no en el de lesión ${ }^{77}$. Y se trata, por lo menos en algunos casos, de delitos cuya legitimidad no es cuestionada, como el falso testimonio del art. 442. Es bastante dudoso, por lo demás, que normas rectoras como el art. 11 puedan informar la interpretación de la parte especial porque, como observa Fincke, toda generalización aplicada al tipo particular marca una tendencia contraria al estado de derecho y al principio de legalidad ${ }^{78}$.

\section{Función de paréntesis}

El principio de legalidad es un producto de la codificación que se hace operativo en la parte especial del código penal; y la complejidad de una pretensión sistemática de la parte especial vinculada a la idea de legalidad es respetar la individualidad de cada uno de los delitos, al tiempo que son clasificados en familias de delitos. En este punto quizás sea conveniente volver a Merkel, pues él tenía claro que aquello que hoy cuenta como función integradora (él la llamaba "la esencia general del crimen" ${ }^{79}$ ) era solo un aspecto de la parte general de la ciencia del derecho penal; los otros aspectos eran la esencia general de la pena, la conexión existente entre crimen y pena, y, finalmente, "todo aquello que es determinado de forma general para el contenido y la aplicación de las leyes penales especiales (criterios de dosificación punitiva, prescripción, etc.)"80. Fincke se refiere a esta variedad de aspectos como la "heterogeneidad" de la parte general ${ }^{81}$.

\footnotetext{
${ }^{74}$ Fincke, 1975, p. 27; Tiedemann, 1992, p. 7.
}

${ }^{75}$ Urs Kindhäuser denomina este enfoque, críticamente, como "paradigma de la agresión”; KINDHÄUSER, 1989, pp. 163-171.

76 Sobre este concepto BiNDiNG, 1902, p. 9.

77 Sobre la distinción entre daño de lesión y daño de peligro, KindHëUSER, 1989, pp. 166-168.

${ }^{78}$ FincKe, 1975, p. 10. Acerca de un "cambio de paradigma" en la relación entre derechos fundamentales y ius puniendi, en donde este es controlado y, además, impulsado por estándares materiales independientes de la voluntad del legislador y jurídicamente vinculantes, BASCUÑ́́n, 2007, pp. 48 y 53 ; en contra de la “constitucionalización” del derecho penal, KuHLEN, 2009, p. 402.

\footnotetext{
${ }^{79}$ Merkel, 1874 , p. 7.

${ }^{80}$ Merkel, 1874, p. 7.

${ }^{81}$ FINCKE, 1975, p. 22.
} 
Además, Merkel creía que la contraposición entre parte general y parte especial en el código penal debía tomarse cum grano salis porque "[1]a parte especial se separa de nuevo, mediante un desarrollo ulterior, naturalmente en partes con relativa independencia, las cuales, a su turno, nuevamente desagregan una parte general que frente al contenido restante de la respectiva subdivisión está en la misma relación que la anteriormente mencionada parte general frente a la totalidad de la especial" 82 .

Es decir, Merkel no veía una "mezcolanza" en los distintos tipos de la parte especial necesitada de homogeneización; por el contrario, consciente del peligro que acecha a los proyectos asimiladores, generalizó de la parte especial aquello que es susceptible de generalizarse, esto es, "la esencia general del crimen", y, conforme con un desarrollo ulterior de la propia parte especial, subdividió la parte especial de acuerdo con su naturaleza. El siguiente fragmento, con el que Merkel cierra la introducción de su estudio de la parte especial del derecho penal alemán, es ilustrativo de ese proceder: "La compleja naturaleza de los numerosos tipos de delito y la diferencia de perspectivas mediante las cuales son separados unos de otros excluye la posibilidad de estructurar aquel orden [el de la parte especial] de acuerdo a un sistema lógicamente satisfactorio. Pero eso no es muy importante. Lo que importa es que los tipos de delito en particular reciban una correcta caracterización" 83 .

Mediante esta estrategia diferenciadora Merkel logra respetar la individualidad de cada delito, es decir, lo especial de la parte especial, al tiempo que clasifica los delitos en familias. Teniendo en cuenta la complejidad de esta tarea no parece correcto asignarle al estudio de la parte especial un estatus científico inferior al del estudio de la parte general $^{84}$. La herencia merkeliana nos deja, entonces, el siguiente saldo, incompatible con la función integradora: la relación entre la parte general y la parte especial del derecho penal no reproduce la relación lógica existente entre un género y su especie, ni a nivel legal ni a nivel teórico; es decir, la parte general del derecho penal no contiene en sí a la parte especial.

Finalmente, Merkel entendía que la parte general del derecho penal también incluía "todo aquello que es determinado de forma general para el contenido y la aplicación de las leyes penales especiales (criterios de dosificación punitiva, prescripción, etc.)" 85 . Las disposiciones respecto de prescripción contenidas en la parte general, de acuerdo con el ejemplo de Merkel, aplican a todas las disposiciones de la parte especial. Esta forma de relacionar disposiciones de la parte general mediante su ubicación al lado de disposiciones de la parte especial se conoce en la doctrina alemana como la función de paréntesis de la parte general en su relación con la parte especial ${ }^{86}$.

La función de paréntesis alude a una metáfora tomada de las matemáticas, pues de acuerdo con la ley matemática de distributividad la cifra que va antes del paréntesis

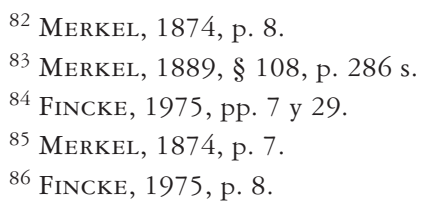


afecta a todo el contenido del paréntesis; de acuerdo con esta metáfora, entonces, las disposiciones de la parte general, ubicadas antes del paréntesis, aplican a todos los delitos de la parte especial, los que, en esta metáfora, están ubicados dentro del paréntesis ${ }^{87}$. Lo general de la parte general, de acuerdo con la función de paréntesis, radica en que las normas de la parte general valen para todas las normas de la parte especial; y su utilidad consiste en que la ubicación de una norma en la parte general evita tener que repetir esa norma al lado de cada uno de los tipos penales de la parte especial. Sin embargo, es claro que esta función de paréntesis no se predica de todas las normas de la parte general $^{88}$; esta es, como ya se dijo, heterogénea. Aparte de las disposiciones acerca de prescripción, ya mencionadas, valen para toda la parte especial las disposiciones relativas a la vigencia de la ley, así como aquellas disposiciones que se ubican al lado de los tipos penales de la parte especial, ampliándolos, como las que regulan la tentativa y la participación. En todo caso, esta función de paréntesis no significa que la parte general contenga al contenido del paréntesis; antes bien, de acuerdo con dicha función, ambas partes, la general y la especial, se encuentran en una relación recíproca de complemento ${ }^{89}$.

\section{PRIORIDAD DE LA PARTE ESPECIAL}

La relación de complemento que se desprende de la función de paréntesis resalta la diferencia cualitativa que existe entre la parte general y la parte especial del derecho penal. La parte general del código penal, alemán y colombiano, se compone de reglas de validez y aplicación de las normas del código penal, así como de reglas de imputación; a su turno, la parte especial se compone de normas de comportamiento que sirven a la protección de bienes jurídicos ${ }^{90}$. Estas normas de comportamiento, que subyacen a las normas de sanción de la parte especial, se interpretan de acuerdo con el bien jurídico que pretenden proteger; mientras que las reglas de imputación de la parte general sirven a la fundamentación de la pena y se interpretan, por eso, de acuerdo con los fines de la pena $^{91}$. La parte general no sabe de bienes jurídicos, es ciega frente al bien jurídico, y por eso no puede fundamentar ningún injusto penal; esta es tarea de los tipos penales específicos, ellos constituyen la "esencia" de la parte especial y en ellos reside el centro del injusto: "[S]olo la parte especial, no la general, define al crimen"92. Atendiendo a la relación entre normas de comportamiento de la parte especial y reglas de imputación

87 Tiedemann, 1992, p. 7, con ulteriores referencias en el pie de página 4; Roxin, 2006, § 1/15, p. 7; KINDHÄUSER, 2017b, § 1/3, p. 29; acerca del significado de esta metáfora, Roxin, 1997, § 10/14, p. 283, nota explicativa de los traductores marcada con asterisco; acerca del significado histórico de la metáfora, como razón que explica el desacoplamiento de la parte general de la especial, FinCKe, 1975, p. 8.

${ }^{88}$ Fincke, 1975, p. 32; Duff, 2007, p. 3.

${ }^{89}$ Fincke, 1975 , pp. 20 y 32.

90 Tiedemann, 1992, p. 11.

91 Tiedemann, 1992, p. 13.

92 Fincke, 1975, p. 28. 
de la parte general puede afirmarse una prioridad lógica de la parte especial sobre la general, porque las reglas de imputación presuponen el comportamiento antinormativo ${ }^{93}$.

\section{La función de la parte especial y la función de la parte general}

La prioridad lógica de la parte especial frente a la general se deja explicar, siguiendo a Paul H. Robinson, en términos funcionales. En su esfuerzo por "organizar" el derecho penal estadounidense ${ }^{94}$, Robinson sostiene que un código penal cumple, al menos, dos funciones. La primera, "debe anunciar al público general, ex ante, las normas de comportamiento que deben hacerse cumplir con sanciones penales" 95 . La segunda, "debe adjudicar, ex post, cualquier infracción de esas normas [de comportamiento]" 96. La función ex ante es prioritaria frente a la función ex post, pues "no puede imponerse responsabilidad en ausencia de infracción a esas normas [de comportamiento]"97-98. La primera función expuesta por Robinson, anunciar al público qué comportamiento está jurídico penalmente prohibido y qué comportamiento está jurídico penalmente mandado ${ }^{99}$, la cumple el código penal colombiano con su parte especial. Pero esto presupone comprender que a las normas de sanción ${ }^{100}$, visibles en la parte especial, subyacen normas de comportamiento, tesis que se remonta a la teoría de las normas de Binding ${ }^{101}$. De esta forma, el código penal colombiano le anuncia al público general que está prohibido matar asociando, en el art. 103, pena de prisión con el comportamiento de "matar a otro".

La segunda función expuesta por Robinson, adjudicar responsabilidad por el quebrantamiento de una norma de comportamiento, la cumple el código penal colombiano con las reglas de imputación contenidas en la parte general. La responsabilidad penal por el homicidio del art. 103, por ejemplo, exige, en condiciones ordinarias ${ }^{102}$, que el autor conozca que su comportamiento cuenta como causa del resultado muerte, caso en el que se le imputará el homicidio a título de dolo, de acuerdo con el art. 22. En algunas ocasiones también se puede hacer responsable al autor bajo condiciones extraordinarias.

\footnotetext{
93 Mañalich, 2009, p. 79.

94 Robinson, 1997, pp. IX y 3.

95 Robinson, 1997, p. 8, bastardilla en el original.

96 Robinson, 1997, p. 8, bastardilla en el original.

97 Robinson, 1997, p. 157.
}

98 Acerca de las consecuencias de esta división funcional respecto del principio de legalidad penal, Robinson, 2005, pp. 375-377.

${ }^{99}$ Una norma de comportamiento se compone de un operador deóntico y de la descripción del contenido de la norma; Vogel, 1993, p. 34. Los operadores deónticos son: prohibición (algo no debe ser llevado a cabo), mandato (algo debe ser llevado a cabo), permisión (algo tiene derecho a ser llevado a cabo) y exención (algo tiene derecho a no ser llevado a cabo); von Wright, 1963, p. 71; Alchourrón y Bulygin, 2012, p. 60. Un modelo así es llamado “cuadrado deóntico"; Joerden, 2018, p. 181.

${ }^{100}$ Una norma de sanción se compone de un supuesto de hecho y de una consecuencia jurídica negativa; KindHÄUSER, 1989, pp. 13 y 29.

101 Binding, 1922, p. 35 ss; Binding, 1885, p. 155.

102 Acerca de la distinción entre imputación ordinaria y extraordinaria, HruSCHKA, 1991, p. 456. 
Por ejemplo, si alguien ignora que su comportamiento cuenta como causa del resultado muerte, pero ha debido saberlo de acuerdo con el art. 23, se le imputará el homicidio culposo del art. 109. Asimismo, el autor, doloso o culposo, de homicidio se reputa culpable en condiciones ordinarias, de acuerdo con el art. 32.11, si en virtud del conocimiento de lo injusto del homicidio ha debido formar la intención de no matar. En algunas ocasiones también se puede reputar culpable al autor bajo condiciones extraordinarias. Por ejemplo, de acuerdo con el art. 33, segundo párrafo, cuando el autor del 103 o del 109 haya causado el motivo excusante. En todo caso, los arts. 22 (dolo), 23 (culpa), 32.11 (error de prohibición) y 33, segundo párrafo (actio libera in causa), no tienen un espacio propio de aplicación con independencia de las normas de comportamiento a las que están referidos. Y eso significa, justamente, que la parte especial es prioritaria frente a la general ${ }^{103}$.

\section{Los destinatarios de la parte especial y los destinatarios de la parte general}

Una consecuencia de la distinción funcional recién expuesta es la correlativa distinción entre el destinatario de una y otra norma ${ }^{104}$. En el marco del derecho penal estadounidense "[e]s una vieja idea, aunque poco atendida, que la ley puede establecer una distinción entre las reglas dirigidas al público en general y las reglas dirigidas a los funcionarios" 105 . Resulta interesante destacar que, en opinión de Meir Dan-Cohen, esa idea ha sido poco atendida en virtud de una "concepción demasiado simple de la relación entre los dos tipos de regla" ${ }^{106}$; por el contrario, tomarse en serio la relación evita lo que Dan-Cohen llama una "comprensión reduccionista”, es decir, la "conclusión de que un conjunto único de reglas es en principio suficiente para cumplir tanto la función de guiar las decisiones oficiales como la de guiar el comportamiento del público"107. En particular, Dan-Cohen es consciente de que la importancia de las normas de comportamiento en la aplicación del derecho por parte de los jueces no implica una reducción a este tipo de normas; se trata, como se dijo atrás, de una prioridad lógica que deja intacta

${ }^{103}$ Esta distinción funcional entre parte especial y parte general, si bien tomada de la doctrina del derecho penal estadounidense, no es unánime en dicho contexto. Así, por ejemplo, Michael S. Moore, quien por lo demás defiende una comprensión funcional del derecho, distingue la parte general del derecho penal de la especial trazando una línea entre teorías descriptivas y teorías normativas, correspondiendo la parte general a una teoría descriptiva del derecho penal y la parte especial a una teoría normativa del derecho penal; Moore, 1997, p. 9 s; acerca de la comprensión funcional del derecho de Moore, Moore, 1992, pp. 208217. En el derecho penal inglés R.A. Duff invita a abandonar la distinción en términos categoriales y, en su lugar, a entenderla como "la forma más clara y conveniente de explicar el derecho"; Duff, 2007, p. 4.

${ }^{104}$ Robinson, 2005, p. 377 s.

105 Dan-Cohen, 1984, p. 625; la distinción en mención se puede rastrear, en la doctrina estadounidense, hasta George P. Fletcher, quien menciona "la rica distinción", que él toma de la doctrina penal alemana, entre wrongdoing y subjective attribution; FLETCHER, 1978, p. 455. Es interesante resaltar que Fletcher inicia su libro con la parte especial, como un "débito con la tradición legal anglo-americana"; FLeTCHER, 1978, p. xxii.

106 DAN-COHEN, 1984, p. 625.

107 DAN-Cohen, 1984, p. 627. 
la posibilidad de existencia de reglas de imputación independientes de las normas de comportamiento $^{108}$.

La distinción entre destinatarios de normas de comportamiento y destinatarios de reglas de imputación no significa que ciudadanos y jueces vivan en mundos separados; los jueces, por ejemplo, también "oyen” el mensaje de la norma de comportamiento y, por eso, imponen sanciones al ciudadano que quebranta dicha norma ${ }^{109}$. La doctrina alemana se refiere a este aspecto como la función de evaluación de la norma de comportamiento $^{110}$. Pero desagregar los destinatarios permite realzar, de una parte, los "deberes de cumplimiento de ciudadanos individuales" contenidos en la parte especial y, de otra, los "criterios para responsabilizar a las personas por sus actos" propios de la parte general ${ }^{111}$. En una democracia ambos aspectos son el resultado de la deliberación política ${ }^{112}$; sin embargo, "tiene poco sentido" dirigir las reglas de imputación a los ciudadanos, mientras que dirigir al ciudadano las normas de comportamiento permite que él "cumpla su deber" 113 .

\section{IV. ¿NuEVo ENFOQUe DE LA PARTE ESPECIAL?}

Una comprensión de la relación entre parte especial y general del derecho penal que se rija por los criterios de prioridad de la parte especial sobre la general y de independencia entre ambas partes proporciona un enfoque para el estudio de la parte especial que, si bien ya ha sido explorado en la doctrina alemana, resulta nuevo en Colombia. Aunque parezca una obviedad, la idea de vinculación a la ley presupone a la parte especial pues en ella se materializa el mandamiento de lex stricta asociado a la comprensión actual del principio de legalidad ${ }^{114}$. Esta es una razón histórica de peso que, sumada a la comprensión funcional de la relación entre la parte especial y la general del derecho penal, despeja el camino para una adecuada sistematización de la parte especial. En esa sistematización, por ejemplo, el estudio del homicidio es ajeno al estudio de las teorías de la causalidad y del dolo ${ }^{115}$ y el estudio de los delitos contra el patrimonio económico es ajeno a los criterios de autoría y participación ${ }^{116}$.

Contar con un desarrollo científico de la parte especial brinda a las cortes criterios, previamente sometidos a la discusión académica, para la correcta interpretación de los tipos penales; esa era la idea de Binding a inicios del siglo pasado. Disponer de esta

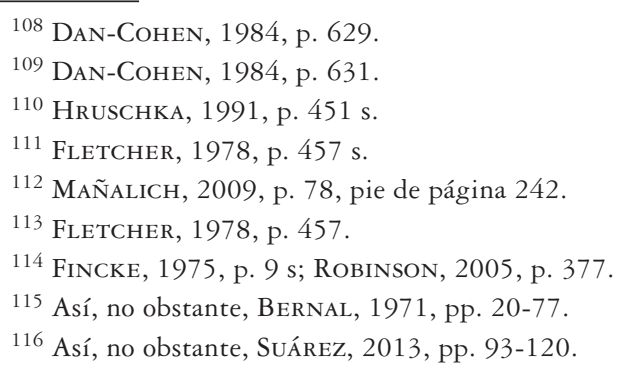


"dogmática del derecho existente" 117 se opone al ejercicio de descubrir, por medio de la razón, qué cuenta como delito. Desechada esa práctica iusnaturalista podría acotarse el estudio de parte general a las reglas sobre validez y aplicación de las normas del código penal y a las reglas de imputación ${ }^{118}$.

\section{BIBLIOGRAFÍA}

Alchourrón, Carlos E., Bulygin, Eugenio, 2012: Sistemas normativos. Introducción a la metodología de las ciencias jurídicas ( $2^{\circ}$ edición), Buenos Aires y Bogotá: Astrea.

Apel, Karl-Otto, 1973: Transformation der Philosophie, Tomo II, Fráncfort del Meno: Suhrkamp.

Aragón, Arcesio, 1938: Código penal anotado, concordado y comentado, Bogotá: Librería colombiana Camacho Roldán \& Cia.

Atria, Fernando, 2016: La forma del derecho, Madrid, Barcelona, Buenos Aires y San Pablo: Marcial Pons.

BAScuñán Rodríguez, Antonio, 1997: "Problemas básicos de los delitos sexuales", Revista de derecho (Valdivia), volumen VIII, número especial.

BASCuñán RodrígueZ, Antonio, 2007: "Derechos fundamentales y derecho penal", Revista de estudios de la justicia, $\mathrm{N}^{\circ} 9$.

Bernal Pinzón, Jesús, 1971: El homicidio, Bogotá: Temis.

BInding, Karl, 1885: Handbuch des Strafrechts, Tomo I, Leipzig: Duncker \& Humblot.

BInding, Karl, 1902: Lehrbuch des gemeinen deutschen Strafrechts. Besonderer Teil (2 edición), Tomo I, Leipzig: Felix Meiner.

BInding, Karl, 1922: Die Normen und ibre Übertretung (4ºdición), Tomo I, Leipzig: Felix Meiner.

Brandom, Robert B., 2000: Articulating Reasons, Cambridge y Londres: Harvard University Press.

Comisión de Asuntos Penales y Penitenciarios, 1938: Trabajos preparatorios del nuevo código penal ( $2^{\circ}$ edición), Tomo I, Bogotá: Imprenta Nacional.

Comisión de Asuntos Penales y Penitenciarios, 1939: Trabajos preparatorios del nuevo código penal, Tomo II, Bogotá: Imprenta Nacional.

Comisión Redactora del Código Penal, sin fecha: Actas del nuevo código penal colombiano, Tomo I, sin ciudad: Colección pequeño foro.

Comisión Redactora del Código Penal, 1981: Actas del nuevo código penal colombiano, Tomo II, sin ciudad: Colección pequeño foro.

Dan-Cohen, Meir, 1984: "Decision Rules and Conduct Rules: On Acoustic Separation in Criminal Law", Harvard Law Review, volumen 97, $\mathrm{N}^{\circ} 3$.

De-La-Vega, Orlando, 2019: "Über den Einfluss der deutschen Straftatlehre in Kolumbien”, en Böse, Schumann y Toepel (editores), Festschrift für Urs Kindhäuser, Baden-Baden, Nomos, pp. 107-117.

Delgado Calderón, Sergio, 1979: Derecho penal especial, Bogotá: Librería jurídica Wilches.

DufF, R.A., 2007: Answering for Crime. Responsibility and Liability in the Criminal Law, Oxford y Portland: Hart Publishing.

117 BINDING, 1885, p. VII.

118 Incluso en la tradición del common law parece conveniente desagregar el estudio de la parte general de "cualesquiera valores morales o políticos subyacentes que puedan ser relevantes para la comprensión normativa del derecho penal”; DuFf, 2007, p. 4. 
Feuerbach, Paul Johann Anselm, 1799: Revision der Grundsätze und Grundbegriffe des positiven peinlichen Rechts, Tomo I, Erfurt: in der Henningschen Buchhandlung.

Feuerbach, Anselm, 1828: Lebrbuch des gemeinen in Deutschland gültigen peinlichen Rechts $\left(10^{\circ}\right.$ edición), Giessen: Georg Friedrich Heyer.

Fincke, Martin, 1975: Das Verbältnis des Allgemeinen zum Besonderen Teil des Strafrechts, Berlín: J. Schweitzer.

Fletcher, George P., 1978: Rethinking Criminal Law, Boston y Toronto: Little, Brown and Company.

Garraud, R., 1888: Traité théorique et pratique du droit pénal français, Tomo I, París: L. Larose et Forcel.

Garraud, R., 1912: Précis de droit criminel (11 edición), París: Librairie de la société du recueil Sirey.

Hart, H.L.A, 1961: The Concept of Law, Oxford: Clarendon Press.

Hart, H.L.A., 1982: Essays on Bentham, Oxford: Clarendon Press.

Hälschner, Hugo, 1855: Das preußische Strafrecht, Tomo I, Bonn: Adolph Marcus.

HäLsChner, Hugo, 1868: Das preußische Strafrecht, Tomo III, Bonn: Adolph Marcus.

Hälschner, Hugo, 1881: Das gemeine deutsche Strafrecht, Tomo I, Bonn: Adolph Marcus.

HäLschner, Hugo, 1884: Das gemeine deutsche Strafrecht, Tomo II, Bonn: Adolph Marcus.

Hefendehl, Roland, 2003: "Das Rechtsgut als materialer Angelpunkt einer Strafnorm”, en Hefendehl, von Hirsch y Wohlers (editores), Die Rechtsgutstheorie, Baden-Baden, Nomos, pp. 119-132.

HrusChKa, Joachim, 1991: "Verhaltensregel und Zurechnungsregel”, Rechtstheorie, volumen 22.

JAковS, Günther, 2001: "Materielle Vollendung bei Verletzungsdelikten gegen die Person. Zugleich ein Beitrag zur Verallgemeinerung des Besonderen Teils", en Schünemann, Achenbach, Bottke, Haffke y Rudolphi (editores), Festschrift für Claus Roxin zum 70. Geburtstag, Berlín y Nueva York, De Gruyter, pp. 793-810.

JAkoBs, Günther, 2003: “Zum Begriff des Delikts gegen die Person”, en Bernsmann y Ulsenheimer (editores), Bochumer Beiträge zu aktuellen Strafrechtsthemen. Vorträge anlässlich des Symposions zum 70. Geburtstag von Gerd Geilen, Colonia, Berlín, Bonn y Múnich, Carl Heymanns, pp. 63-78.

JАковs, Günther, 2008: "Rechtsentzug als Vermögensdelikt. Zugleich ein Beitrag zur Verallgemeinerung des Besonderen Teils", en Sieber, Dannecker, Kindhäuser, Vogel y Walter (editores), Strafrecht und Wirtschaftsstrafrecht. Dogmatik, Rechtsvergleich, Rechtstatsachen. Festschrift für Klaus Tiedemann zum 70. Geburtstag, Colonia y Múnich, Carl Heymanns, pp. 649-661.

Joerden, Jan C., 2018: Logik im Recht ( $3^{\circ}$ edición), Heidelberg: Springer.

KIndHäUser, Urs, 1989: Gefährdung als Straftat, Fráncfort del Meno: Vittorio Klostermann. KIndHÄuser, Urs, 2017a: Strafrecht. Besonderer Teil (9 edición), Tomo II, Baden-Baden: Nomos. Kindhäuser, Urs, 2017b: Strafrecht. Allgemeiner Teil ( $8^{\circ}$ edición), Baden-Baden: Nomos.

Köstlin, C. Reinhold, 1858: Abhandlungen aus dem Strafrechte, Tubinga: H. Laupschen Buchhandlung. Kubiciel, Michael, 2013: Die Wissenschaft vom besonderen Teil des Strafrechts, Fráncfort del Meno: Vittorio Klostermann.

Kuhlen, Lothar, 2009: "Anmerkungen zum Verhältnis von Strafrecht und Verfassungsrecht", en da Costa Andrade, Antunes y Aires de Sousa (editores), Ars Ivdicandi. Estudos em homenagem ao Prof. Doutor Jorge De Figueiredo Dias, Tomo I, Coimbra, Universidade de Coimbra, pp. 401-420.

López Medina, Diego Eduardo, 2004: Teoría impura del derecho, Bogotá, México D.F., Buenos Aires, Caracas, Lima y Santiago: Legis.

Mañalich, Juan Pablo, 2009: Nötigung und Verantwortung, Baden-Baden: Nomos.

MaÑalich, Juan Pablo, 2019: "Verallgemeinerung als Pathos. Zu Günther Jakobs' Beitrag zur Dogmatik des Besonderen Teils”, en Kindhäuser, Kreß, Pawlik y Stuckenberg (editores), 
Strafrecht und Gesellschaft. Ein kritischer Kommentar zum Werk von Günther Jakobs, Tubinga: Mohr Siebeck, pp. 613-643.

Mañalich Raffo, Juan Pablo, 2020: Estudios sobre la parte especial del derecho penal chileno, Santiago: Thomson Reuters.

Maurach, Reinhart, 1959: Deutsches Strafrecht. Besonderer Teil (3 edición), Karlsruhe: C.F. Müller. Merkel, Adolf, 1874: "Ueber das Verhältniss der Rechtsphilosophie zur positiven Rechtswissenschaft und zum allgemeinen Theil derselben”, Zeitschrift für das privat- und öffentliche Recht der Gegenwart, volumen I.

Merkel, A., 1889: Lebrbuch des Deutschen Strafrechts, Stuttgart: Ferdinand Enke.

Moore, Michael S., 1992: "Law as a Functional Kind", en George (editor), Natural Law Theory, Nueva York: Oxford University Press, pp. 188-242.

Moore, Michael S., 1997: Placing Blame, Nueva York: Oxford University Press.

Moore, Michael S., 2002: "Legal Reality: A Naturalist Approach To Legal Ontology", Law and Philosophy, volumen 21, $\mathrm{N}^{\circ} 6$.

Peñas Felizzola, Aura Helena, 2006: Génesis del sistema penal colombiano, Bogotá: Doctrina y Ley.

PÉrez, Luis Carlos, 1968: Tratado de derecho penal, Tomo III, Bogotá: Temis.

RaZ, Joseph, 1975: Practical Reason and Norms, Londres: Hutchinson \& Co.

Robinson, Paul H., 1997: Structure and Function in Criminal Law, Nueva York: Oxford University Press.

Robinson, Paul H., 2005: "Fair Notice and Fair Adjudication: Two Kinds of Legality", University of Pennsylvania Law Review, volumen 154.

Rossi, P., 1872: Traité de droit pénal (4º edición), Tomo II, París: Librairie de Guillaumin et Cie).

Roxin, Claus, 1997: Derecho penal. Parte general (trad. de la 2 edición alemana por Luzón, García y Remesal), Tomo I, Madrid: Civitas.

Roxin, Claus, 2006: Strafrecht. Allgemeiner Teil (4º edición), Tomo I, Múnich: C.H. Beck.

Stern, David G., 2004: Wittgenstein's philosophical investigations. An introduction, Cambridge, Nueva York, Melbourne, Madrid, Ciudad del Cabo, Singapur y San Pablo: Cambridge University Press.

SuÁrez SÁnchez, Alberto, 2013: Delitos contra el patrimonio económico (2 edición), Bogotá: Universidad Externado de Colombia.

Tiedemann, Klaus, 1992: "Zum Verhältnis von Allgemeinem und Besonderem Teil des Strafrechts”, en Arzt, Fezer, Weber, Schlüchter y Rösner (editores), Festschrift für Jürgen Baumann, Bielefeld, Ernst und Werner Gieseking, pp. 7-20.

Vogel, Joachim, 1993: Norm und Pflicht, Berlín: Duncker \& Humblot.

von Wright, Georg Henrik, 1963: Norm and Action, Londres: Routledge \& Kegan Paul.

\section{Jurisprudencia citada}

BGHST. 9, 62, en: Entscheidungen des Bundesgerichtshofes in Strafsachen, tomo 9 (1955), pp. 62-64.

Corte Suprema de Justicia. Sentencia de 13 de febrero de 1963, en: Gaceta Judicial, tomo CI (1963), pp. 325-338.

Corte Suprema de Justicia. Sentencia de 29 de julio de 1965, en: Gaceta Judicial, tomos CXIII y CXIV (1974), pp. 281-289.

Corte Suprema de Justicia. Sentencia de 14 de diciembre de 2011, en: Jurisprudencia E Doctrina, $\mathrm{N}^{\circ} 485$ (2012), p. 823.

Corte Constitucional. Sentencia de 15 de abril de 2021. Sentencia C-093. 